Revista de Investigación Educativa $\mathbf{2 8}$

enero-junio, 2019 | ISSN 1870-5308 | Xalapa, Veracruz

Instituto de Investigaciones en Educación | Universidad Veracruzana

\title{
Una educación estética en la era de la globalización ${ }^{1}$
}

Raúl Homero López Espinosa ${ }^{a}$

DOI: $\underline{\text { https://doi.org/10.25009/cpue.v0i28.2607 }}$

Spivak, G. C. (2017). Una educación estética en la era de la globalización. [Trads. C. M. Fraga con la colaboración de I. Villegas \& G. Dietz]. México: Universidad Nacional Autónoma de México-Dirección General de Artes Visuales-Instituto de Investigaciones Estéticas/Universidad Autónoma Metropolitana/Palabra de Clío/Fundación Universidad de las Américas Puebla/Siglo XXI. 566 pp. ISBN: 978-607-03-0863-5.

Gayatri Chakravorty Spivak, junto con Edward Said y Homi K. Bhabha, con$\mathcal{U}$ forman una triada de autores fundamentales para los estudios poscoloniales. Parte de la contribución que hace la pensadora india a estos estudios la hallamos en Una educación estética en la era de la globalización, compilación de veinticinco ensayos presentados, en años anteriores, como discursos inaugurales o ponencias en distintos espacios académicos. El libro se publicó originalmente en 2012 y, para esta primera edición en español, Christopher Michael Fraga estuvo a cargo de la

1. Agradezco a la Mtra. Roxana Zermeño Rivas por mejorar la redacción de este trabajo.

${ }^{a}$ Doctor en Literatura Hispanoamericana. Secretaría Académica, Universidad Veracruzana, México. 凶raullopez01@uv.mx 
traducción, en la cual colaboraron Irlanda Villegas y Gunther Dietz. Imposible pasar por alto que, gracias a la tarea de traducir un libro como éste, pertinente y casi obligado para las ciencias sociales y las humanidades en Latinoamérica, se facilita el propósito de difundirlo.

En el Prólogo, la autora explica de manera concisa el sentido de cada uno de los ensayos y, además, confía al lector vivencias personales por las que atravesaba al escribirlos; entre otras, el poco tiempo que tenía para prepararlos, la partida de su pareja, la muerte de su amigo Bimal Krishna Matilal, la vergüenza que le daba hablar de flatulencias al explicar el problema de la identidad, las inseguridades intelectuales que cargaba consigo por el sexismo sufrido desde su época escolar, las dudas que le surgían porque quizá no expresó lo que esperaban de ella quienes la invitaban a componer sus disertaciones. El relato de estas circunstancias parece marginal, pero no lo es. Se asoma en él un cuestionamiento a lo que Aimé Césaire llamó "universalismo descarnado" en el eurocentrismo.

Uno de los reclamos a los estudios poscoloniales es la supuesta domesticación de su objeto de investigación, al convertirlo en texto para analizarlo desde la teoría literaria. Lo cierto es que con ello concibieron una perspectiva teórica aguda, creativa e innovadora, difícil de obviar en el contexto actual de las ex colonias. Así, el libro muestra la utilidad de la crítica literaria para estudiar la cultura y el presente poscolonial e historiar los efectos del colonialismo. He ahí la clave: como la globalización ocurre en el "aparato sensorial del ser experimentador" (p. 17), la educación estética es necesaria. ¿De qué índole es esta educación? Es lo que Spivak expondrá a lo largo de los ensayos.

El problema de la hegemonía y la subalternidad es medular. El interés de la modernidad europea en torno a la razón y el conocimiento no es tan puro como se nos ha vendido; en las principales obras filosóficas o literarias subyacen narrativas legitimadoras del dominio europeo sobre el resto del planeta. En particular, el libro se concentra en el imperio británico en la India. La hegemonía de la que hablamos no se reduce al ámbito de la economía o la política, sino que se expande a la cultura y la epistemología. Nos encontramos ante una colonización epistemológica de la otredad o "violación epistémica” —-metáfora sugerente que aparece en Crítica de la razón poscolonial —. ¿Qué significa esto?

En Una educación estética... se explica que los textos literarios tienen un lector implícito construido dentro un "sistema consolidado de representación cultural" (p. 6o). Así, cuando la literatura de una hegemonía es leída por individuos en posición 
de subalternidad emerge un proceso de enajenación. Spivak se refiere a la "carga del inglés" en la India. El problema no es que éste sea una herramienta de comunicación, sino que se asuma como la vía para apreciar la literatura. El inglés moldea el pensamiento del subalterno para hacerlo corresponder con los patrones y valores culturales dominantes. Sucede, entonces, una identificación placentera con la literatura hegemónica, el sujeto exclama “isí, sí!” al leerla, lo que conlleva una colonización sutil de la manera en que pensamos, percibimos o sentimos.

La "violación epistémica" no es perpetrada exclusivamente por Europa; Spivak sugiere que hay una complicidad entre la élite nativa en los territorios antes colonizados y los principios del imperialismo. Es decir, la hegemonía nacionalista impulsa una colonización interna, en la cual los intelectuales juegan un rol protagónico. Conforman una inteliguentsia funcionaria: "un colchón — dice Spivak- entre los gobernantes extranjeros y los gobernados” (p. 86). ¿Por qué un colchón? Porque generan una representación del subalterno y, tal representación, implica conocimiento y éste, a su vez, dominio.

Un concepto más que enriquece la comprensión de lo que esta inteligencia significa, y que usa la filósofa para autodenominarse, es la poscolonial diaspórica. Spivak es una poscolonial diaspórica que produce y simula "el efecto de un mundo de antaño, constituido por las narrativas legitimadoras de la especificidad y la continuidad culturales y étnicas" (p. 88). Esculpe o hila una identidad nacional, un "otro" que, finalmente, resulta cómodo para el consumo transnacional. Tal concepto trae consigo una autocrítica hacia la función que desempeña la élite autóctona en la nueva colonización; en él se concentra uno de los problemas centrales planteados en el libro: la poscolonial diaspórica es el sitio de un quiasmo: "el sistema de producción de la burguesía nacional en su país de origen y, en el extranjero, la tendencia a representar el neocolonialismo mediante la semiótica de la 'colonización interna”' (p. 87). Aquí hay un quiasmo y la autora nos reta a rumiarlo. No es solo que al descifrarlo se amplíe la comprensión sobre la lógica colonial, se trata de un caso diáfano de cómo la crítica literaria se yuxtapone con el estudio de la cultura. De hecho, en Spivak hay un cruce entre diversos campos del saber que nos conduce a un universo complejo de sentidos. Otra de las virtudes del libro es mostrarnos cómo puede darse lo que Olga Pompo llama "fecundación recíproca de las disciplinas" y, por ende, tiene su relevancia para el debate actual en torno a la interdisciplina.

Como poscolonial diaspórica, Spivak puede autosinecdoquizarse, es decir, autorepresentarse. Cuando incursiona en la formación de maestros para el subalterno 
deja de lado sus diferencias — nacimiento de casta, profesora de Columbia University que gana en dólares - para representarse como ciudadana india - toma la parte por el todo, como en la sinécdoque-, lo cual le permite conformar una colectividad con sus alumnos tribales, quienes no tienen la libertad de dejar sus diferencias. El subalterno no puede autosinecdoquizarse, carece de capacidad performativa. Esta es otra manera troquelada por Spivak para explicarse al subalterno, inspirada en la idea de Marx acerca de los pequeños campesinos en Francia: "No pueden representarse, sino que tienen que ser representados".

Parte sustancial del proyecto de la autora consiste en "generar la infraestructura para que, cuando sea necesario, cuando la esfera pública lo exija, puedan autosinecdoquizarse - los subalternos_-” (p.483), por eso la prioridad de una educación estética. El libro, pues, es un aporte para la generación de esta infraestructura, de ahí que al final de su Introducción aparezca la falsa ilusión de Spivak: "Que cualquier lector desperdicie el tiempo para aprender a analizar los deseos (a diferencias de las necesidades) de los ejemplos colectivos de la subalternidad" (p. 57).

Cuando Spivak habla de subalternidad tiene en mente, sobre todo, a la mujer. Es así porque está pensando en el sati y la ocupación devadāsi. Se puede discutir entre autoridades coloniales y la élite nacionalista sobre si tales prácticas son bárbaras o parte de una tradición, pero en ningún momento se pide la opinión de las mujeres. Si se escuchara a la subalterna, no como víctima sino como agente, dice Spivak, no nos veríamos obligados a practicar la descolonización “desde arriba”, pero, agrega, no se le escucha. En consecuencia, una de las preguntas filosóficas esenciales en esta descolonización es “iquién descoloniza, y cómo?” (p. 116).

En este marco, el libro nos ofrece una agenda para las "nuevas escuelas de crítica poscolonial” (p. 116). Algunos de sus lineamientos son los siguientes. La educación posibilitaría el ascenso social de las mujeres, pero Spivak no concuerda con una pedagogía de los oprimidos, sino con una reforma en la educación nacional en general. Su filosofía de la educación no consiste en estudiar al subalterno, sino en aprender de él; "aprender a aprender desde abajo" y forjar con ello "hábitos del comportamiento democrático” (p.485). Plantea una pedagogía literaria, des(cons)tructiva que, grosso modo, busca identificar las "fallas en las consignas de la Ilustración europea” (p. 99) —en Crítica de la razón poscolonial se describía como una deconstrucción tropológica: encontrar conceptos-metáfora en la racionalidad pura-. No estamos hablando, por lo tanto, de obviar, rechazar o destruir aquellas consignas, sino de negociar con ellas. Para continuar con la metáfora de la violación epistémi- 
ca, la propuesta es negociar con el falo, tal como aparece en el análisis de Spivak sobre "The Hunt".

¿Qué implica esta negociación? Al menos, la advertencia de la moderación en nuestras posturas. El militante de los estudios poscoloniales -lo mismo funcionaría para los decoloniales - no debería perder de vista el siguiente apotegma de Spivak: "El ser incapaz de percibir error alguno en el otro lado — se refiere al del subalterno - equivale a alimentar la arrogancia de la conciencia neocolonialista benévola” (p. 94).

El lector implícito de Spivak sería aquel que se da el tiempo para meditar la escritura que tiene enfrente, nada sencillo de hacer y menos en la vida hiper acelerada que llevamos. Dice la autora que "si el periodo de concentración del lector es lo suficientemente largo" (p. 203), ella podrá continuar con su exposición y el lector con su lectura. Spivak sostiene que como profesora de humanidades su labor consiste en "expandir la capacidad de aprender y de enseñar a leer en el sentido más firme — no solamente clasificar, registrar y describir-" (p.485); esto es, dar lugar a nuevas formas de leer y escribir (p. 99).

¿Por qué una nueva forma de leer y escribir? ¿Qué papel han tenido la lectura y la escritura en la colonización europea del mundo? ¿Qué papel pueden tener en la práctica de la descolonización? ¿Una educación estética... implica una nueva forma de leer y escribir? Estos son algunos problemas presentes en el libro, que el mismo libro sugiere responder a partir de un diálogo entre autor y lectores. Así como la obra de arte contemporánea está acabada hasta que la termina el espectador, Una educación estética... nos invita a terminar de escribirla desde nuestras circunstancias. 